\title{
A paleo-perspective on the AMOC as a tipping element
}

Stephen Barker ${ }^{1}$ and Gregor Knorr ${ }^{2}$

\begin{abstract}
Ocean circulation within the Atlantic is capable of changing rapidly, with important consequences for global climate. Evidence from various climate archives suggests that abrupt transitions in the past were preceded by systematic behavior that could have provided early warning indicators.
\end{abstract}

The Atlantic Meridional Overturning Circulation (AMOC) redistributes heat, salt and carbon as part of the global thermohaline circulation. Major changes of the AMOC would have global impacts and, as a potential tipping element (Lenton et al. 2008), it is a focus for future projections. The IPCC (2013) concluded that it is very unlikely that an abrupt transition or collapse of the $A M O C$ will occur during the next century for the scenarios considered. However, it is not clear that, under realistic forcing conditions, the complex models used for future climate scenarios are capable of producing the abrupt changes that occurred relatively frequently during the last glacial period (Valdes 2011).

\section{Paleo evidence for abrupt change}

Temperature records obtained from Greenland ice cores provided the first convincing evidence of past abrupt climate change (Fig. 1). The Greenland records revealed repeated transitions (the so-called Dansgaard-Oeschger, D-O, oscillations) between cold, stadial conditions and warmer interstadial conditions, with extremely fast (decades or less) shifts between these states (NGRIP members 2004). These alternations are one expression of a global system, capable of driving major changes in components ranging from ocean temperatures to monsoon rainfall. Massive ice-rafting events across the North Atlantic (Heinrich Events, $\mathrm{HE}$ ) during some stadial phases (HS events) were associated with particularly cold conditions across the North Atlantic (Shackleton et al. 2000) and suggest the existence of three distinct climate "states" during glacial times.

\section{The ocean's role in rapid climate change} It has long been argued that D-O and Heinrich variability involved changes in the AMOC and many attempts have been made to test this using paleodata. On a basin scale, water mass tracers, such as benthic foraminiferal $\delta^{13} \mathrm{C}$ and $\mathrm{Cd} / \mathrm{C}$ a ratios and seawater $\mathrm{Nd}$ isotopes, suggest a reduction in the ratio of northern versus southern deep water end-members in the Atlantic during northern cold events, particularly those associated with $\mathrm{H}$-Events (Shackleton et al. 2000). On a regional scale, variations in the transport of North Atlantic Deep Water have been reconstructed using a variety of methods including sediment composition, grain size and magnetic analysis (Kissel et al. 2008). These studies suggest a systematic link between high-latitude climate change and variations in deep ocean circulation, even for non-Heinrich stadial events. They suggest a reduction in the deep overflows emanating from the Nordic Seas during cold events, implying a decrease in the production of deep waters through open ocean convection north of Scotland. Concomitant variations in wintertime sea-ice cover across the Nordic Seas have been proposed as an effective means of explaining the very large changes in temperature observed across Greenland associated with D-O transitions (Li et al. 2010).

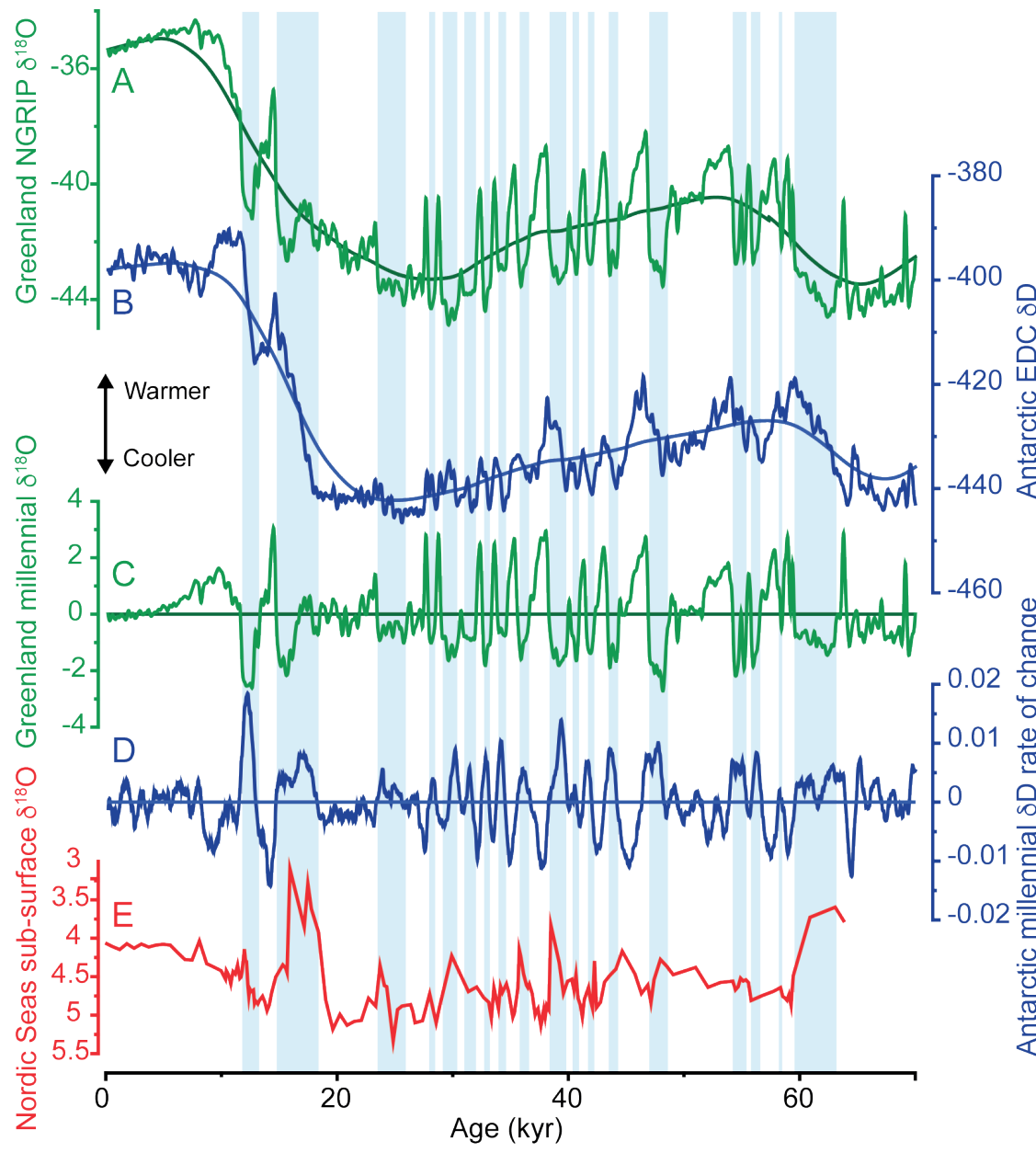

Figure 1: Abrupt climate change over the past $70 \mathrm{kyr}$. The blue bars indicate stadial events. (A) Greenland temperature proxy record showing the abrupt D-O transitions (NGRIP members 2004). Orbital component is a 7 kyr running mean. (B) Antarctic temperature proxy record showing a more gradual behavior (Jouzel et al. 2007). (C) Millennial-scale component of Greenland temperature. (D) Rate of change of Antarctic temperature showing systematic warming during Greenland stadials and cooling during interstadials (Barker et al. 2011). (E) Proxy record showing sub-surface warming in the North East Atlantic during stadial events (Ezat et al. 2014). 


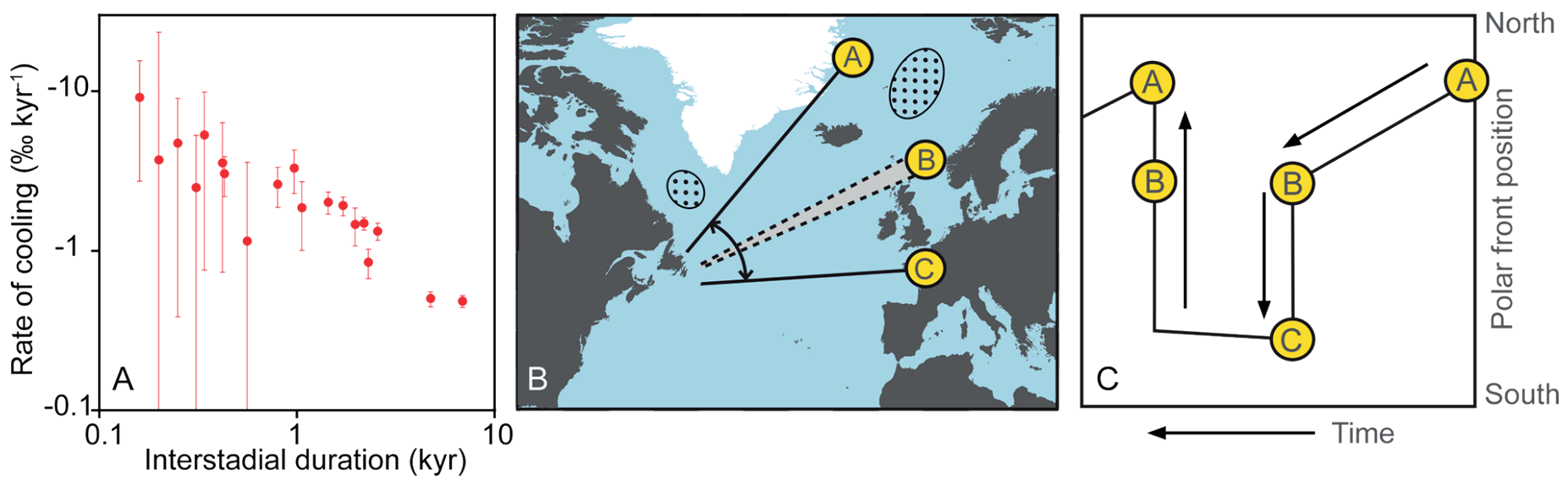

Figure 2: Gradual cooling during an interstadial precedes the abrupt transition to stadial conditions. (A) The rate of cooling (defined here as the rate of change in $\delta^{18} \mathrm{O}$ ) during a Greenland interstadial is related to its duration. (B) Cartoon showing the approximate migration path of the North Atlantic polar front associated with D-O transitions. Stippled areas show approximate locations of modern deep convection. Position A represents interstadial conditions with convection north of Scotland. Stadial conditions are represented by point $C$ with deep convection restricted to south of Iceland. (C) Temporal evolution of the polar front position across a D-O oscillation. From point $A$, gradual cooling pushes the polar front southwards. On reaching threshold point $\mathrm{B}$, an abrupt southward migration of the polar front occurs with the transition to stadial conditions (point C). It can be seen that a faster rate of cooling between A and B would result in a shorter interstadial. The return to warm conditions is essentially synchronous across the North Atlantic. Modified after Barker et al. (2015).

\section{The $A M O C$ as a tipping element}

The magnitude and speed of D-O transitions qualifies as abrupt climate change, yet the nature of the transitions and whether they are "predictable" in some way is debated. Abrupt transitions could be the result of a gradual change in forcing applied to a system containing a threshold (tipping point) or of a large and abrupt change in forcing applied to a system with or without a threshold. In the former case, we could expect "early warning" indicators of the abrupt change as a result of "critical slowing down" as the threshold is approached. A decrease in system resilience close to the bifurcation point would be reflected by an increase in variance and autocorrelation that could be detected given a well-resolved time series of a relevant system parameter. No early warning would be expected for a system without a threshold, or in a system forced through a threshold by a large and rapid change in forcing.

Statistical studies using the Greenland temperature records have produced contrasting results, with early warning being undetected (Ditlevsen and Johnsen 2010) or weakly present (Cimatoribus et al. 2013). Yet there are other reasons to suspect that D-O transitions are the result of gradual forcing through a critical threshold and are not merely stochastic in nature.

The abrupt transitions from interstadial to stadial conditions over Greenland are preceded by gradual cooling during interstadial times (Figs. 1,2). Barker et al. 2015 have argued that this cooling is related to a gradual southward migration of the North Atlantic polar front, giving rise to a diachronous transition to polar conditions across the North Atlantic, and leading to an abrupt descent into stadial conditions once a threshold is crossed (Fig. 2b,c). Such a threshold is also implied by the Greenland temperature records themselves, which reveal an inverse relationship between the rate of cooling within an interstadial and the duration of that event (Fig. 2a).
The abrupt transitions from stadial to interstadial conditions, as recorded by the Greenland temperature records, reveal no systematic behavior prior to these transitions. However, using the Greenland temperature records, one cannot differentiate between $\mathrm{HS}$ events and non- $\mathrm{H}$ stadials even though North Atlantic records suggest much colder conditions during HS events (Shackleton et al. 2000). This can be explained by the insulating effect of sea-ice across the Nordic Seas but implies that the Greenland temperature records are not optimally suited for detecting early indications of impeding interstadial transitions. In contrast, the Antarctic ice core records suggest a continuous build-up of heat across the Southern Ocean throughout all stadial events (Jouzel et al. 2007; Fig. 1d). Moreover, the "Antarctic signal" is not restricted to the remote Southern Hemisphere but can be detected around the Earth as a globally pervasive signal (Barker and Knorr 2007). Furthermore, gradual global warming (that could be the incidental by-product of stadial conditions; Fig. 1) could itself lead to an abrupt strengthening of the AMOC beyond some threshold (Knorr and Lohmann 2007), suggesting that early warning of abrupt warming transitions may be detectable given the right record.

\section{Prone to instability}

The ubiquitous cooling observed throughout interstadial periods, leading ultimately to an abrupt transition to stadial conditions (Barker et al. 2015), suggests that whether or not the interstadial mode of AMOC is dynamically stable, its very existence necessitates a transition back to a stadial mode. Equally, if the build-up of heat during stadial conditions (Jouzel et al. 2007; Ezat et al. 2014) is the ultimate cause of an abrupt switch back to interstadial conditions, it could be argued that neither state is truly stable. Thus, the D-O oscillations may be an inevitable consequence of glacial climate, rather than the consequence of random external perturbations. Indeed, the Antarctic temperature record documents the continuous redistribution of heat throughout stadial and interstadial periods alike (Jouzel et al. 2007; Barker et al. 2011; Fig. 1). According to this metric, the AMOC only ever experiences quasi-equilibrium during full interglacial and full glacial conditions (Barker et al. 2011). Thus from a paleo perspective it appears that abrupt transitions in the AMOC can occur in response to gradual change, even if that change is a product of the AMOC state itself. State-of-the-art climate models should be tested to reproduce this sensitivity to learn more about abrupt climate transitions in the past and place more robust constraints on future predictions of AMOC stability.

\section{AFFILIATIONS}

${ }^{1}$ School of Earth and Ocean Sciences, Cardiff University, UK

${ }^{2}$ Alfred Wegener Institute, Bremerhaven, Germany

\section{CONTACT}

Stephen Barker: BarkerS3@cardiff.ac.uk

\section{REFERENCES}

Barker S et al. (2015) Nature 520: 333-336

Barker S, Knorr G (2007) PNAS 104: 17278-17282

Barker S et al. (2011) Science 334: 347-351

Cimatoribus A et al. (2013) Clim Past 9: 323-333

Ditlevsen PD, Johnsen SJ (2010) Geophys Res Lett 37, doi: 10.1029/2010GL044486

Ezat MM et al. (2014) Geology, doi:10.1130/G35579.1

IPCC (2013) Climate Change 2013: The Physical Science Basis. Cambridge University Press, 1552 pp

Jouzel J et al. (2007) Science 317: 793-796

Kissel C et al. (2008) Paleoceanography 23, doi:10.1029/2008PA001624

Knorr G, Lohmann G (2007) Geochem Geophys Geosyst 8, doi:10.1029/2007GC001604

Lenton TM et al. (2008) PNAS 105: 1786-1793

Li C et al. (2010) J Clim 23: 5457-5475

NGRIP members (2004) Nature 431: 147-151

Shackleton NJ et al. (2000) Paleoceanography 15: 565-569

Valdes P (2011) Nature Geosci 4: 414-416 